\title{
Selective recovery of phenolic compounds and carbohydrates from carob kibbles using water-based extraction
}

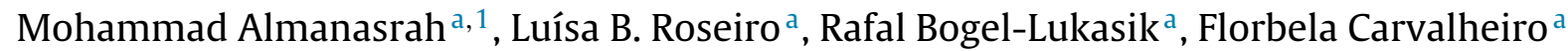 \\ , Carla Brazinha ${ }^{\mathrm{b}}$, João Crespo ${ }^{\mathrm{b}}$, Mari Kallioinen ${ }^{\mathrm{c}}$, Mika Mänttäri ${ }^{\mathrm{c}}$, Luis C. Duarte ${ }^{\mathrm{a}, *}$ \\ a Unidade de Bioenergia, Laboratório Nacional de Energia e Geologia, I.P. (LNEG), Ed. K2, Estrada do Paço do Lumiar 22, $1649-038$ Lisboa, Portugal \\ ${ }^{\mathrm{b}}$ REQUIMTE/CQFB, Department of Chemistry, FCT, Universidade Nova de Lisboa, P-2829-516 Caparica, Portugal \\ ${ }^{\mathrm{c}}$ Laboratory of Separation Technology, LUT Chemtech, Lappeenranta University of Technology, P.O. Box 20, Lappeenranta, FIN-53851, Finland
}

\section{A R T I C L E I N F O}

\section{Article history:}

Received 10 August 2014

Received in revised form 21 January 2015

Accepted 22 February 2015

\section{Keywords:}

Aqueous extraction

Biorefinery

Fermentable sugars

Glucose fructose syrup

Scale-up

\begin{abstract}
A B S T R A C T
Carob kibbles are an important renewable source of valuable compounds, such as fermentable sugars and phenolic compounds. However, the selective recovery of these compounds is not a trivial task. In this work, a strategy was developed to enable the recovery of both classes of compounds by means of a water-based extraction.

One-step extraction recovered only approximately $20 \%$ of the phenolic compounds, corresponding to an extraction yield of $0.6 \mathrm{~g}$ Gallic acid equivalents (GAE)/100 g dry mass of carob kibbles. The obtained extract contained a significant amount of carbohydrates $(110 \mathrm{~g} / \mathrm{L})$. The alternative two-step extraction developed enabled higher compound selectivity together with an increase in the yield of the phenolic compounds to about $70 \%$, corresponding to $1.9 \mathrm{~g}_{\mathrm{GAE}} / 100 \mathrm{~g}$ carob dry matter.

The two-step extraction was easily scaled-up and is an effective method to obtain significantly separated carbohydrates and polyphenol-rich streams that can be further processed, e.g., in biorefineries or food industries, respectively.
\end{abstract}

(c) 2015 Elsevier B.V. All rights reserved.

\section{Introduction}

Agro-food industry wastes, such as olive, grape and carob residues, can be exploited as raw materials for various valuable products, and these agro-food residues have received considerable attention as an abundant and inexpensive renewable resource for chemical, biotechnological and pharmaceutical applications. Carob kibbles, in particular, are recognized as having great potential, not only due to its high content of easily fermentable sugars, but also due to its phenolic content. Carob kibbles are the result of mechanical treatment of carob pods, using a kibbler, after the high-value seeds ( $\sim 10 \%$ of the carob pod weight) have been extracted for the production of locust bean gum (Albergaria et al., 1999). Currently, carob kibbles are mainly used as animal feed, despite its valuable composition. The soluble sugars in carob kibbles can reach up to $50 \%$ on a dry basis (Roseiro

\footnotetext{
* Corresponding author. Tel.: +351 210924600; fax: +351969069117.

E-mail address: luis.duarte@lneg.pt (L.C. Duarte).

1 Permanent address: Laboratory of Separation Technology, LUT Chemtech, Lappeenranta University of Technology, P.O. Box 20, Lappeenranta FIN-53851, Finland.
}

et al., 1991a; Petit and Pinilla, 1995; Avallone et al., 1997) and the kibbles can be used in a wide range of applications, including the production of ethanol, citric acid (Roukas, 1998), xanthan (Roseiro et al., 1991b) and mannitol (Carvalheiro et al., 2011), as well as the specialty chemical pinitol (Macias Camero and Sanjuan Merino, 2003). Several studies have drawn attention to this residue as a good source of valuable phenolic compounds (Owen et al., 2003; Makris and Kefalas, 2004).

The phenolic compounds are a group of very diverse chemicals that include e.g., phenolic acids and aldehydes, hydroxycinnamic acids and its derivatives, flavonoids, lignans, or tannins (Manach et al., 2004). Many of these compounds have been shown to present useful traits that support their use as bioactive compounds for human health. As such, the study of their selective recovery is a significant scientific and industrially applied relevant topic. Moure et al. (2001) reviewed various extraction and recovery methods of antioxidant compounds (mainly phenolic compounds) from agricultural and industrial residues, and this has been complemented by other studies, e.g., considering residues such as olive seeds and olive mill waste water (Paraskeva and Diamadopoulos, 2006; Marco et al., 2007), grape seeds (Casazza et al., 2011), potato peels (Singh and Saldaña, 2011), carob (Turhan et al., 2006), and many other biomass residues (Junior et al., 2010). 